The $B D J$ News section accepts items that include general news, latest research and diary events that interest our readers. Press releases or articles may be edited, and should include a colour photograph if possible. Please direct your correspondence to the News Editor, Arveen Bajaj at the BDJ, The Macmillan Building, 4 Crinan Street, London N1 9XW or by email to bdj@bda.org

\section{Fund marks 125th year anniversary}

The Association of Specialist Providers to Dentists (ASPD) is celebrating the 125th year of the Benevolent Fund with a huge, sponsored cycle ride covering the $125 \mathrm{~km}$ from Birmingham to Oxford on 1 July 2007- that's one kilometre a year.

The Benevolent Fund is a registered charity with a proud history of providing assistance for all registered UK dentists and their families in times of need, whether caused by illness, stress, accident or family breakdown. It relies on the continued support of the dental profession.

If you would like to sponsor an ASPD member, please visit www.justgiving. com/125kmcycle and if you are interested in taking part in the sponsored bike ride, please contact James Forrest at Sports 4 Life UK on 07950395699 or email contact@sport4life.org.uk. For more information on the Benevolent Fund please call Sally Atkinson on 02074864994 .

\section{Alpine victory for RADC}

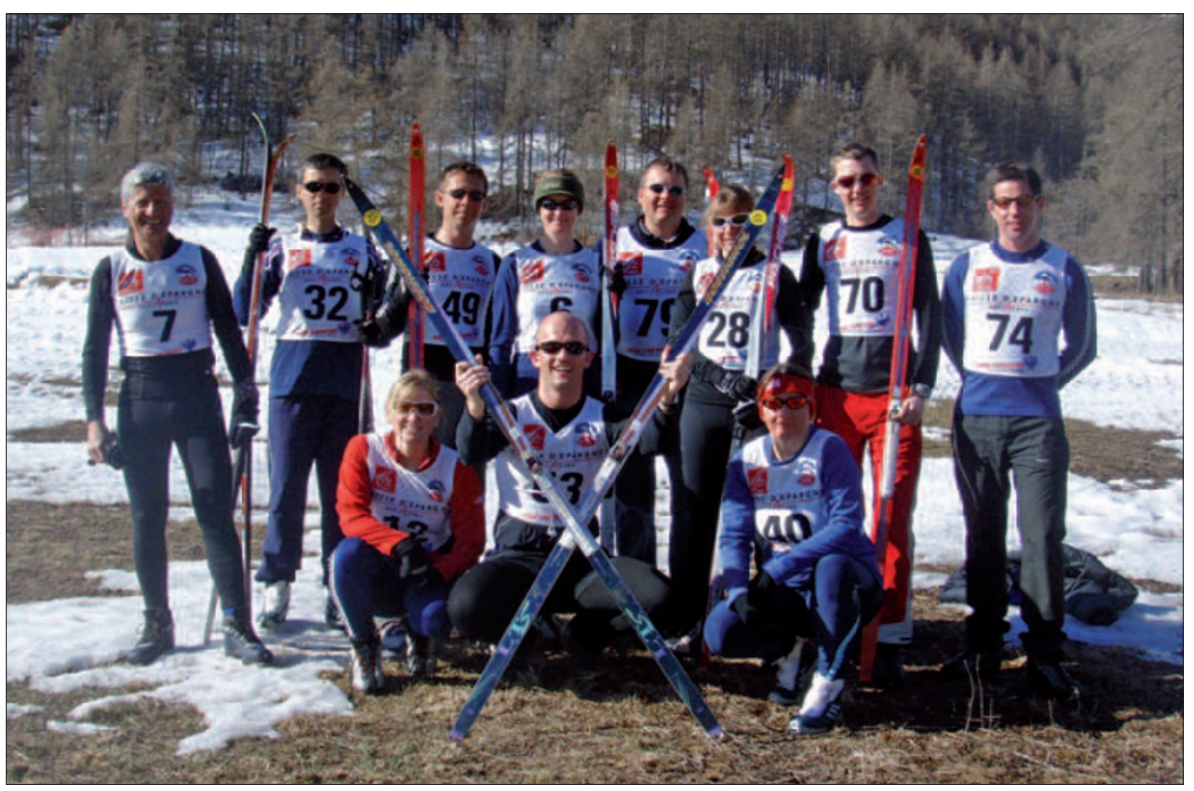

The Royal Army Dental Corps (RADC) Team took part in the annual Army Medical Services Ski Championships in Serre Chevalier, France recently. The team was sponsored by Dentsply and fielded its largest ever team of 22 who competed in both Alpine and Nordic races.

A first week of hard training and second week of competitive skiing resulted in the team collecting an impressive array of silverware. Highlights included the A team's victories in the Slalom and Giant Slalom races with Major Nikki Porter becoming the first female ever to win all the Individual Alpine Trophies when she won not only the Ladies' Special Slalom race but also beat all the men to take the Slalom and Giant Slalom Trophies. The team's Nordic victories included winning the Non Field Unit Cup in the gruelling Medical Patrol Race.

\title{
Have you treated this man?
}

Police are requesting the help of the dental community in order to locate missing person Daniel Hathaway, also known as Nicholas Greengrove. At 5 pm on 7 February 2007, 44-yearold Daniel Hathaway left his home address in Corby, Northants to conduct a business meeting, which was believed to be of a short duration. Daniel left his home with about $£ 2,000$ in cash and has never been seen or heard of since. Daniel's partner reported him as a missing person on the 8th February 2007.
At a very early stage the circumstances of Daniel's disappearance gave grave cause for concern and police have designated his disappearance as a nobody-murder and a major investigation has commenced. To date Daniel's body has not been found.

If you have treated or seen Daniel since January 2007 please contact Operation Beguile by emailing opbeguile@northants.pnn.police.uk, or by post at Homicide and Major Crime Team, Operation Beguile, Elizabeth Street, Corby, Northants, NN17 $1 \mathrm{SH}$.

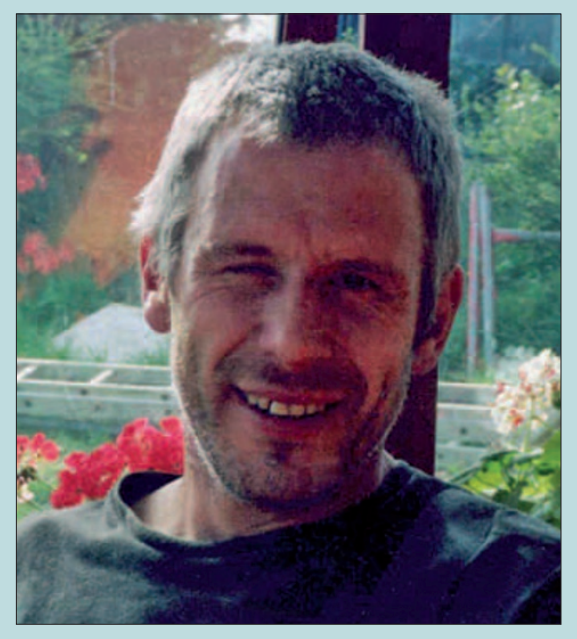




\section{Artistic medical imagery}

Joe Dixon, the artist behind the $B D J$ 's volume 202 cover series, is holding an exhibition of his work next month. The London-based artist works primarily with medical imagery and his work with the $B D J$ explored twelve oral diseases. In the exhibition, his use of detailed painting techniques is evident in his series of human cross sections and his use of bold colour and painting style explore every aspect of human anatomy, creating a labyrinth of visual stimulus.

The show will run from 13-26 July 2007 at St Pauls Art Space, St Stephens Church, St Stephens Road, London, E3 5JL. Visit www.stpaulsartspace.org. uk, www.jdarts.co.uk or email info@ jdarts.co.uk for more information.

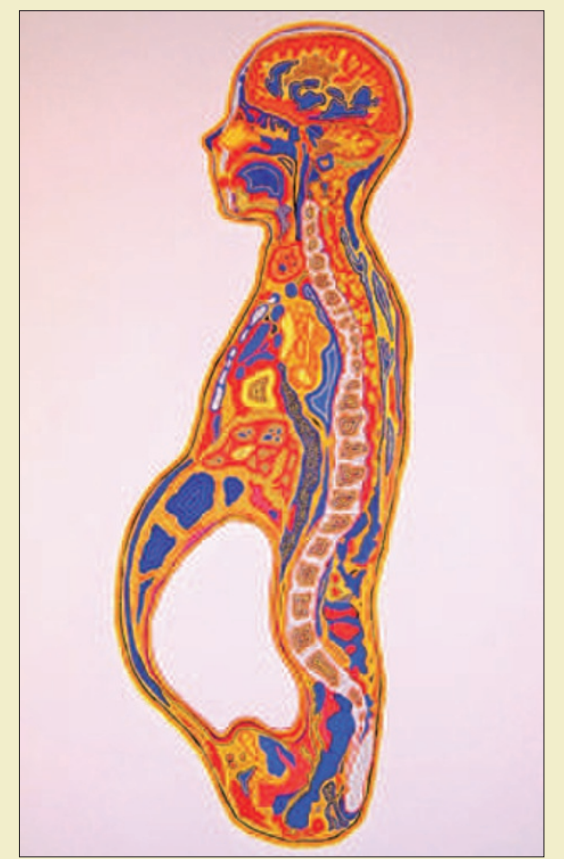

One of the exhibits

\section{Toothpaste alert}

The US Food and Drug Administration (FDA) has warned consumers in America to avoid using toothpaste made in China, and has issued an import alert to prevent toothpaste containing the poisonous chemical diethylene glycol (DEG) from entering the United States. DEG is used in antifreeze and as a solvent. Out of caution, FDA suggests that consumers throw away such toothpastes due to concern that these products may contain diethylene glycol, also known as diglycol or diglycol stearate.

\section{Telephone 'quit lines' do help}

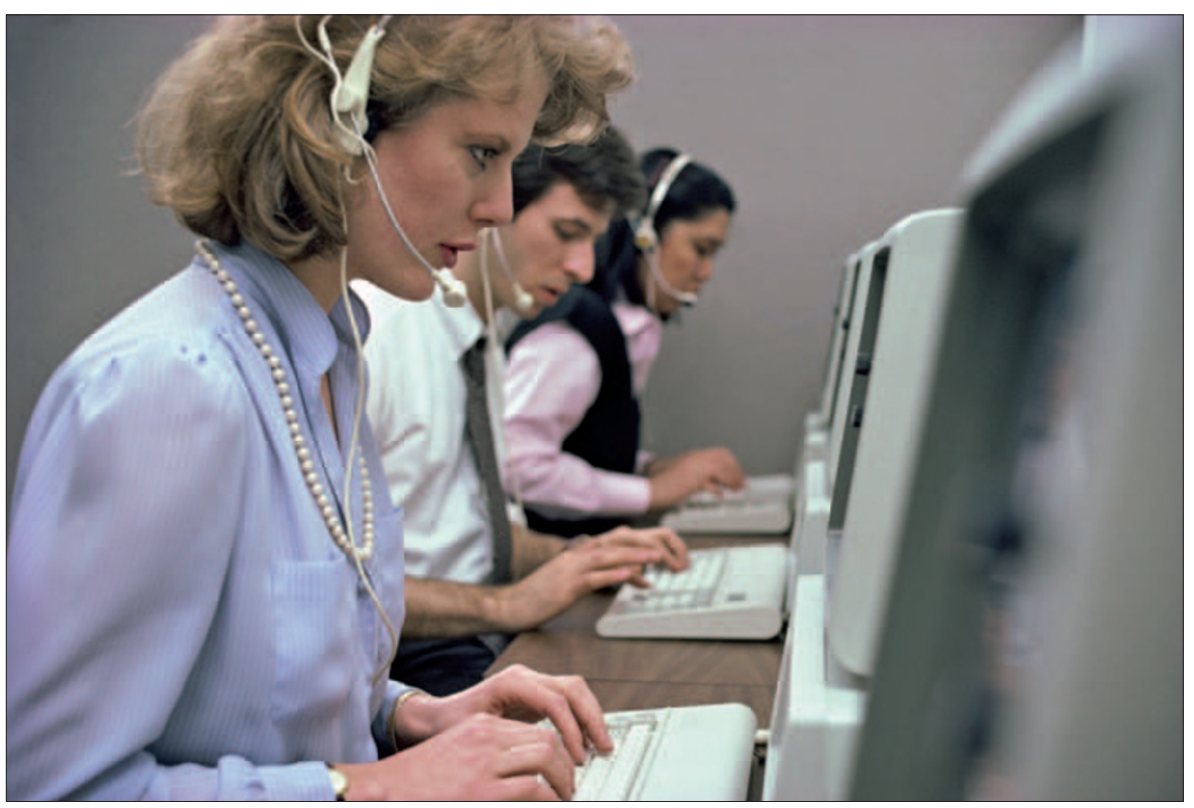

Dentists may be able to help their patients stop smoking by referring them to tobacco-use telephone 'quit lines' according to a pilot study published in the Journal of the American Dental Association (2007; 138: 595-601).

Researchers at the Mayo Clinic College of Medicine, Rochester, Minnesota, USA, identified the need to conduct a pilot study to evaluate whether the speedier measure of referring patients to tobacco use quit lines was also effective in helping patients stop smoking.

Dentists who intervene with patients to help them stop using tobacco can play a significant role in decreasing tobaccorelated illness and death. However, providing support for such patients requires time and resources that oral health care professionals may not always have.

The authors randomly assigned eight general dental practices in Minnesota to provide either brief counselling regarding smoking cessation or brief counselling along with referrals to a tobacco-use quit line for patients who reported that they were currently smoking cigarettes.

of 82 patients, 60 were referred to the tobacco-use quit line and 22 received only brief counselling. At six months, 25\% of the patients in the quit line group and $27.3 \%$ of the patients in the brief-counselling group had abstained from tobacco use. Abstinence rates among patients in the quit line group rose if those patients completed more telephone consultations.

The authors cite research indicating that although more than $60 \%$ of dentists believe their patients do not expect tobacco-use cessation services from them, about $59 \%$ of patients believe that dentists should provide such services.

\section{New President installed}

The Anglo-Asian Odontological Group (A0G) recently voted in Dr Nadeem Zafar as their new President for 20072008. Dr Zafar said, 'I look forward to building on the phenomenal work done by our outgoing President of two years, Dr Rishi Mehrotra, and taking the AOG forward in being recognised as a leading dental organisation for social, educational and charitable activities.'

The AOG is calling for all its members to get in touch and update their contact details. For further information, please visit www.aoguk.org.

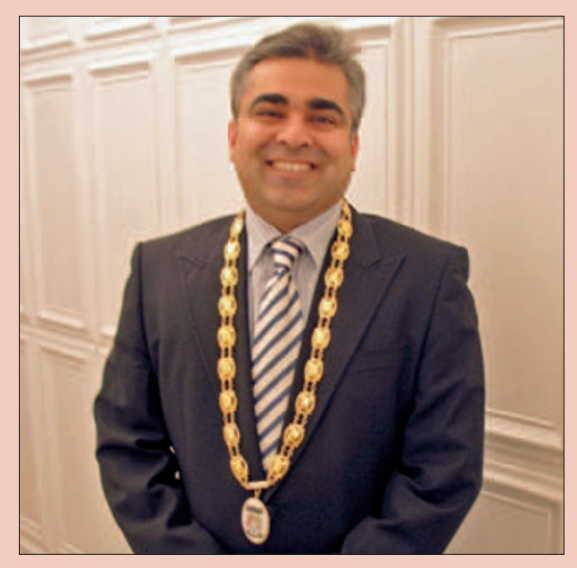




\section{Avulsed teeth - a request for patients}

A paediatric study looking at children with avulsed teeth is requesting patients for participation. The study is a multi-centred randomised controlled trial involving five centres (Leeds, Glasgow, Belfast, Newcastle and the Eastman, London).

Referrals are invited of suitable children who have avulsed and had replanted a permanent tooth or teeth. The trial will look at the success of two follow up protocols. Children can be accepted onto the trial where the initial replantation and splinting has been carried out by a general dental practitioner, community dentist or within a hospital setting (A\&tE or maxillofacial surgery).

Please refer the child to the nearest centre as soon as possible after the emergency treatment (replantation and splinting), since to be included in the trial they must be seen within ten days. Each patient requires five visits to the participating dental hospital over a period of one year where all follow-up treatment for the avulsed tooth will be provided.

As this is a paediatric study, only children under the age of 16 will be admitted and suitable children will be consented by staff at the dental hospital. Those children referred but unwilling or not fulfilling the inclusion criteria will not prejudice the care they receive.

For more details of the inclusion criteria or any other information, please contact Peter Day on 07963054090 or by email on p.f.day@leeds.ac.uk. Alternatively, please contact the Principal Investigator at each centre:

- Royal Belfast Hospital for Sick Children and School of Clinical Dentistry - Dr Terry Gregg

- Leeds Dental Institute - Dr Peter Day and Professor Monty Duggal

- Glasgow Dental School Professor Richard Welbury

- The Eastman Dental Institute (London) - Dr Paul Ashley

- Newcastle Dental School Dr Ben Cole.

\section{Charity offers hope to disfigured children}

The British Academy of Cosmetic Dentistry's (BACD) charitable foundation 'Smiling for the World' is helping children living with facial disfigurement. It has selected children's charity 'Facing the World' as the primary focus of its support. BACD volunteer members waived their fees to carry out tooth whitening with kits donated by Discus Dental and patients undergoing tooth whitening were then able to contribute their treatment costs directly to the charity.

'Facing the World' is an inspirational charity that offers hope to children in the developing world who are born with severe facial disfigurements. The charity gives these children a chance to receive the miracle of a new face and a life free from stigma in some of the world's poorest countries.

Although BACD has been pleased with the support and donations received so far, their target is to raise $£ 100,000$ for the vital work of this charity. If only one third of BACD's 620 members signs up then they can meet this target. For

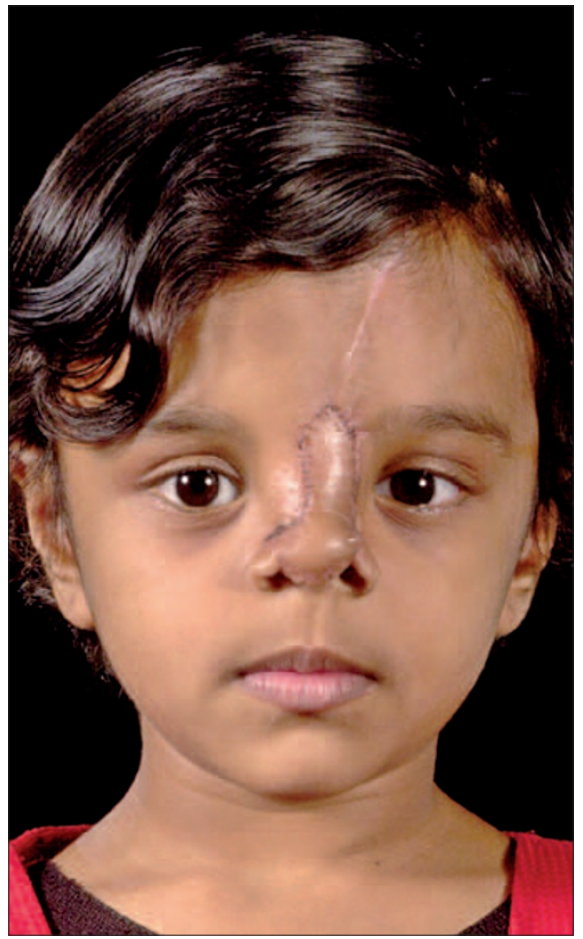

Kalyani was born with a complex facial cleft in central India, which resulted in two large ridges on her forehead, a limited nose and eyes significantly displaced. She is pictured here post-op.

more information please contact the BACD on 02082418526 , email info@ bacd.com or visit www.bacd.com or www.facingtheworld.net. 


\section{DIARY}

July

BDA Armed Forces Group AGM

Date: 5 July 2007

Venue: BDA Lecture Theatre, London

Tel: 01296656469

\section{September}

4th Annual Meeting of the European Society of Esthetic Dentistry

Date: 21-23 September 2007

Venue: Vienna, Austria

Email: iris.bobal@media.co.at

www.escdonline.eu

148th American Dental Association

Annual Session and Marketplace

Exhibition

Date: 27-30 September 2007

Venue: The Moscone Center,

San Francisco, USA

www.ada.org

\section{October}

British Society of Oral Implantology Inaugural Symposium

Date: 6 October 2007

Venue: The University of Glamorgan

Email: support@BSOI.org

www.BSOl.org

Oral Cancer: Challenges and Solutions

Date: 6 October 2007

Venue: Eastman, London

www.eastman.ucl.ac.uk

BDTA Dental Showcase

18-20 October 2007

Date: 18-20 October 2007

Venue: NEC Birmingham

Tel: 01494789959

www.dentalshowcase.com

Annual meeting of the Society of Craniofacial Genetics \& American

Society of Human Genetics Meeting

Date: 23 October 2007

Venue: Convention Center, San Diego,

California, USA

www.craniofacialgenetics.org

FDI Annual World Dental Congress

Date: 24-27 October 2007

Venue: Dubai, UAE

Email:congress@fdiworldental.org

www.fdiworldental.org

\section{Bid for Britain won}

The British Orthodontic Society has won the bid to host the eighth meeting of the World Federation of Orthodontists (WFO) in the UK in 2015. The news is a major coup for the BOS as well as for London, which is likely to welcome in the region of 10,000 orthodontists from around the world for the event.

The WFO consists of 105 organisations from 100 countries as well as 6,500 individual orthodontists who have become WFO Fellows. The international meeting takes place every five years and the next one is in Sydney in 2010.

London was chosen over Barcelona, Toronto and Mexico City at the American Association of Orthodontists meeting in Seattle last month. British orthodontist Allan Thom, who is on the WFO Executive Committee representing Europe, paid tribute to Jonathan Sandler, who is the UK member of the Council of the WFO and having led the bid for BOS, is now Chairman of the Eighth International Conference. He said, 'I am absolutely thrilled that we

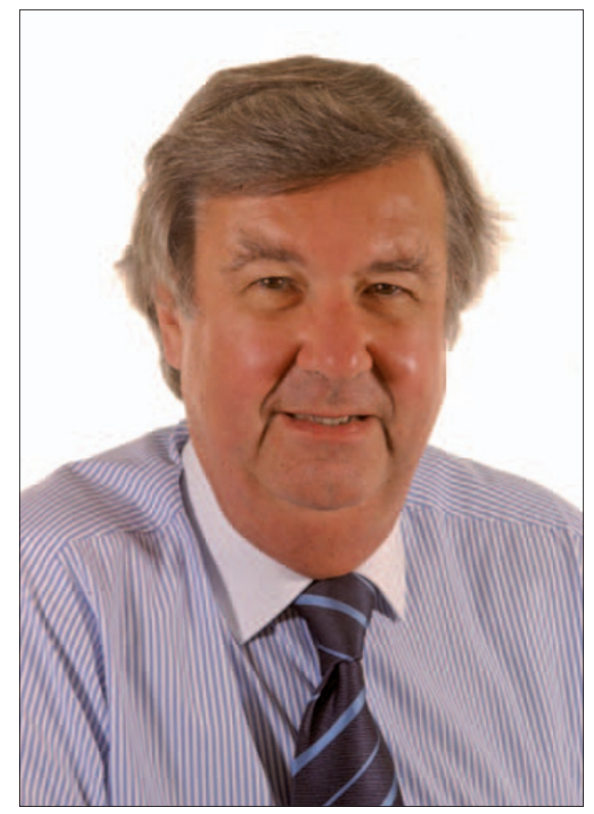

Allan Thom

have won although I appreciate the enormity of the task ahead. With the help and co-operation of my able and willing team in the UK and friends around the world I hope to make this event a fantastic success.'

\section{More training in oral cancer detection needed}

More than 92\% of Illinois dentists provide oral cancer examinations for their patients, but many are not performing the procedures thoroughly or at optimum intervals, according to a new study from the University of Illinois at Chicago, (UIC) USA.

With an incomplete understanding of the nature of pre-malignant lesions and of proper examination techniques, some dentists in Illinois are not doing all they should to detect oral cancers in their patients, according to Charles LeHew of the UIC Cancer Center's Center for Population Health and Health Disparities and the Institute for Health Research and Policy.

More than 500 dentists in 19 Illinois counties responded to the 38-item questionnaire that was used to gauge the extent of their knowledge of oral cancer prevention and early detection. The majority of dentists correctly identified squamous cell carcinoma, the most common form of oral cancer, as well as the most common sites for oral cancer and the most-common types of early lesions. Many, how- ever, were not able to answer those questions correctly.

Moreover, dentists lacked knowledge needed for risk assessment and counselling. Two-thirds of the dentists had had oral cancer continuing education; however, 40\% had trained more than two years prior to the survey. Dr Linda Kaste, Associate Professor of Prevention and Public Health Sciences who co-authored the study said, 'Illinois dentists face many barriers to providing early detection and risk counselling services to their patients. Lack of proper training and adequate time appear to be chief among them.'

She added that to increase awareness of the disease, UIC has been working with organisations in several Illinois counties that have high incidences of oral cancer to develop and distribute public health education materials. Oral cancer screenings are also provided to the underserved populations. The counties are located in northeast, central, western, and southwestern Illinois. The study was published in the Journal of Public Health Dentistry 2007; 67: 89. 